\title{
The Impact of Employee Sycophantic Behaviour on Organisation Environment: A Conceptual Study of Hospitality Sector in India
}

\author{
Chahal HS ${ }^{1}$ and Poonam B $^{2 *}$ \\ ${ }^{1}$ Guru Nanak Dev University, Gurdaspur, Punjab, India \\ ${ }^{2}$ Guru Nanak Dev University, Amritsar, Punjab, India
}

\begin{abstract}
In today competitive environment, sycophantic behaviour played in every organisation significant role and the organisation environment also influenced by this behaviour. If we go into deep discussion, we realize as well that this behaviour is behaviour to get competitive advantage for personal growth. It is also observed that, performance of organisation depends upon the surrounding as read in many HRM books that "Good environment leads to good performance of any companies". Service industry required team spirit for increasing performance level and for that behaviour is generally being adopted by the employees to please their bosses. Some questions arise like: 1) what does sycophancy means? 2) How does it influence the environment? And does have positive impact on employee Performance? To do Oiling and battering to their bosses to get promotion and good place in the industry is known as sycophancy. According Ekong and Essien, the sycophantic groups are those who involve more in intrigues, lying about others to cause confusion-official liar and those who pretend to be the adviser to the political leader. But their false praise performance and outputs may vary. The above matter can be seen in private sector as well in public or government sector also at some extent. But if we talk about government sector, Jhatial found in his study that $80 \%$ of respondents in government sector agreed that connection or sifarish, references, sycophancy and cronyism play significant role in HRM decision making process whereas only $20 \%$ of respondents found that it have done on merit based decision.
\end{abstract}

Keywords: Sycophancy behaviour; Organisation environment; Competitive advantage; Promotion; Transformation; Recruitment and selection; Decision making

\section{Introduction}

\section{Meaning of sycophancy}

Sycophancy means flattery which is very obedient, or it is an indication of deference to another to gain advantage, and to an excessive or servile degree. A person or employee of sycophancy is referred to as a sycophant. A sycophant is a person who tries to win favor from wealthy or influential people by flattering them only to again selfadvantage. In other words, sycophantic person acts towards someone powerful in order to gain advantage either in the form of promotion or good position in the industry $[1,2]$.

Sycophant is a servile self-seeker who attempts to win favour by flattering influential people. A person who fawns, deferential and grovelling, abject, adulatory, bootlicking, bowing, brownnosing, compliant, cowering, crawling, cringing, flattering, humble, ingratiating, kowtowing, mealy-mouthed, obsequious, parasitic, prostrate, scraping, servile, slavish, spineless, submissive and subservient. According to Ekong and Essien [1] sycophantic groups often feed political class with information, often distorted, garnished with lies and unfounded optimism, from the polity. Ayodele [3] believed that Sycophancy has degree or level. It also has magnitude, direction and effect.

Earlier sycophantic behaviour begins in the educational system, but criticism is never supported by institutions from the starting. There are various factors' helps in reducing or tolerating criticisms like perks, benefits and privileges of power etc. People, who criticize, are most often disparaged, as they are called as complainers. Therefore, intolerance views of others are the indicators of sycophancy.

Henry [4] stated - when an adult takes his/her place in an organization, the human interaction and reaction begins which are based on human biases or mistakes which they make instead of on fairness, the merit and objectivity. The expression, used by many Americans which are unsaid national slogan for them is "going along to get along". A sycophant is "the one who always seeks favour by flattering and praising people of wealth or influence them" according to Webster's New World Dictionary. Hence, it is clear that Sycophants do not make any kind of waves or criticisms.

\section{Definitions of sycophancy}

According to Fasahnu [5], sycophancy behaviour is a situation which may be created by a medium continues to praise government or individuals despite ills which might be weakness or incompetence in office [6]. "A sycophant reporter is a journalist who flatters political leaders, wealthy citizens and owners of the media houses who as employers have dread power over and against journalist".

Richie [7] sycophancy is any attempt to please someone on authority to get personal advantage. Therefore, a sycophant is a servile person, who acts for their own interest, attempts to win favour by flattering one or more persons of influence.

\section{How Sycophantic Behaviour Influence the Environment}

As Judge and Bretz [8] found that influencing behaviour effect

*Corresponding author: Poonam B, Guru Nanak Dev University, Gurdaspur, Punjab, India, Tel: 09855227014; E-mail: Poonambabouria@gmail.com

Received July 28, 2015; Accepted August 18, 2015; Published August 22, 2015

Citation: Chahal HS, Poonam B (2015) The Impact of Employee Sycophantic Behaviour on Organisation Environment: A Conceptual Study of Hospitality Sector in India. Arts Social Sci J 6: 117. doi:10.4172/2151-6200.1000117

Copyright: (c) 2015 Chahal HS, et al. This is an open-access article distributed under the terms of the Creative Commons Attribution License, which permits unrestricted use, distribution, and reproduction in any medium, provided the original author and source are credited. 
career success and they found the positive effect on career growth. In the present study, it was examined trust as an important factor that influence other person to again advantage and for building trust, communication was found necessary between each other to avoid confusion. Study suggested sycophantic behaviour is required somewhere, otherwise colleagues would take advantage or your junior worker take the advantage so everyone should have this art. Sycophantic behaviour was also compared with machine like after some period of times it required oiling to make machine work properly and similarly time to time employees also oil their bosses. Being a sycophantic person the individuals found taking number of advantages just by putting litter effort like oiling their bosses and presenting themselves as there are more efficient and committed to industry than others, sometimes even they take credit for another employee's work. They do only to take position in the company, authority, promotion, to be part in the decision making process, to have hold in the recruitment and selection process and transformation should be in their hand. So we say very sycophantic person have two face there is no point to say that this statement is wrong.

\section{Advantages of having sycophancy behaviour}

Advantages of having sycophancy behaviuor is shown with the help of Figure 1- 1) Sycophantic behavior=Promotion, Transformation, Decision making and Recruitment and selections.

\section{Literature review of sycophantic behaviour}

Judge and Bretz [8] conducted a study and found effect of sycophantic behaviour influenced the career success which showed that sycophancy behaviour had positive effect on career growth. Also influence of sycophancy behaviour and career success was compared. Survey method used and 651 sample size was taken from Midwestern university, respondent were graduate of the industrial relations program from university. Findings of the study showed "apple polishing seems to be a better means of getting ahead than blowing one's own horn" positive effect of sycophantic behaviour on successful career.

Thacker and Wayne [9] conducted a study to investigate subordinate influence tactics of sycophantic behaviour and individual differences on perceptions of supervisor's promo ability. Sycophantic tactics taken in the study were ingratiation, reasoning, and assertiveness and selfreports. Survey was done on both supervisors and subordinates and

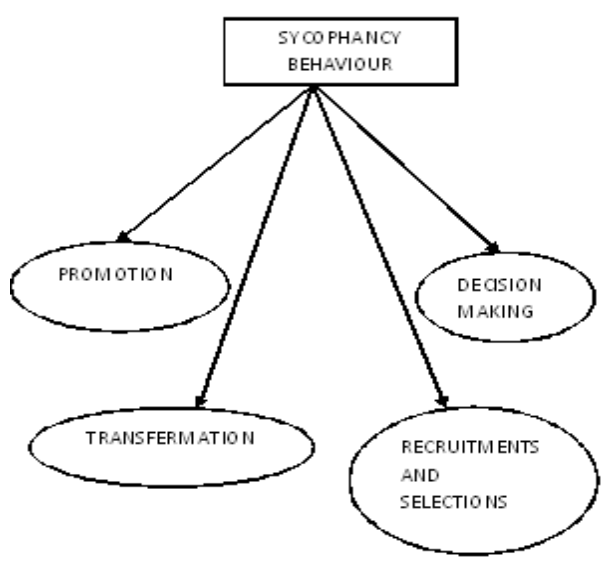

Figure 1: Advantages of having Sycophancy behavior, shown with the help of diagram. relationship among influence tactics and promo ability. It was found assertiveness was not a good tactic for any employee to engage in and supervisors feel that assertive employees are trying to take control. Secondly, it was also found "Reasoning" as a subtler approach of sycophantic behaviour and most persuasive influence tactic. Reasoning involved the subordinate working with the supervisor and providing detailed action plans, logical arguments, facts and careful explanations.

Drane [10] conducted a study to find out their relationship among sycophantic behaviour, supervisor-subordinate communication, coworker relationships and trust. These three variables were studied to examine their good relationships between co-workers and the effect of these relationships on the organization. "sycophantic behaviour" with relation to promotion in an organization as well as the best sycophantic influence style, relationship of "supervisor-subordinate communication" was studied and their effect on job satisfaction and employee motivation and the final variable "Trust" have been discussed to examine the benefits of trust to the organization's longevity, productivity and efficiency. The study revealed that the relationships developed between the supervisors and subordinates through different communication behaviours such as immediacy, reciprocity and accommodation was found positive work environment for both the supervisor and subordinate. The second variable result that good coworker relationships leads to job satisfaction and finally concluded that trust among employees was related to their job satisfaction, therefore it improves the organizations longevity, productivity and efficiency.

Umeogu [11] conducted a study on Nigerian media and focused on sycophancy and objective journalism. He evaluated the elements of sycophancy, ethics, objectivity, objectivity journal and looked at the reasons that effect on public, media house, individuals and the government. In this study causes of sycophancy and its danger effects on entire professions was discussed. Study concluded that objectivity in journalism was attainable and relative to those journalists who were more to be ethical or not willing to face the challenges. Finally study discussed various causes of Sycophancy i.e. Lack of experience on the part of Political leaders, Poverty, Environmental contingencies, Lack of professional education or training of journalists.

Mangi et al. [12] conducted the study and investigated that sifarish i.e. sycophancy or connection and nepotism. It was found that these were critical factors in HRM functioning. This study also investigated that sifarish or connection affects the decisions like recruitment, selection and promotions while developing functions of HRM in private sector. Findings revealed that cultural factor influenced HRM Functioning's. Collectivism, sifarish, cronyism and sycophancy strongly influenced factors on HRM practices in the private organisations.

Ekong and Essien [1] conducted a study to unveil the surrounded operational forces and compelling of gangsterism and sycophancy in Nigerian polities. He examined the level of influence on politic decision by economic factors. The study has developed a model to analyse gang and sycophantic politics in Nigeria. The study revealed that the gang, to a large extent, influence the appointment of political office holders such as ministers, commissioners, advisors etc. study also discussed various characteristics of gang and sycophantic groups in Nigeria such as suspicion, strong capacity to convince leaders, attractiveness, flexibility, sycophantic, blackmail and lies, diabolical and deceitfulness. Results suggested that influence and patronizing role of gangs and sycophant must equally be discouraged, which intern down play the power and influence the money politic in the nation. 


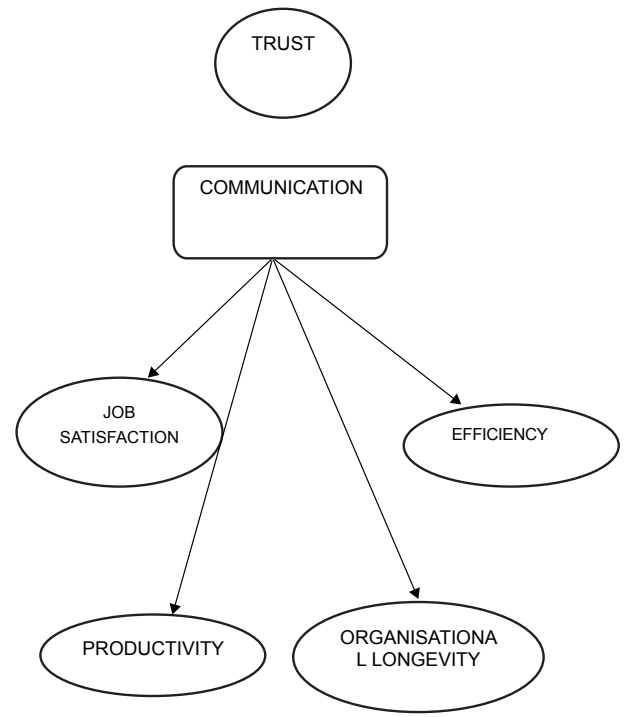

Figure 2: Organizational longevity and efficiency.

\section{Advantages of trust and communication}

After reviewing literature, most of the studies showed that trust having relation with Communication. As Drane [10] discussed in the study and conclude that if the communication flow is good in the company it leads to job satisfaction, productivity, Organizational longevity and efficiency. This is shown with the help of diagram (Figure 2). Krafft et al. also discussed about trust relationship through perception and fairness[13].

\section{Impact of Sycophantic Behaviour on Organisation Environment}

After reviewing literature, the researchers Judge and Bretz [8] found in their study that influencing behaviour had positive effect on career success and in career growth, and also found that if the employee gets career success then they must be committed to their organisation. Drane [10] also discussed that sycophantic does have positive influence on career growth and also discussed that, there must be proper communication and trust factor which directly or indirectly lined with organisation Environment. As Cool and Wall [14] in their study examined that trust is one of the factors between individual or group which highly responsible for employee work stability for long term of the organisation or being a part for long time. Study suggested, if a person is trustworthy and has sycophantic behaviour and uses it in right way, then there is no harm to carry such kind of attitude but at some extent only.

If we talk about communication it is a process to convey messages or information by two ways i.e. may be in written form and may be in verbal from but if the flow of communication is in right way, and in right direction then it will create motivation in employee and the industry will grow. If both the factors present in service industry (Trust and communication) it will result less turnover, absenteeism, Job satisfaction, Productivity and more commitment. If these factors are present in the Organisation then this will reduce the company cost and time and the more focus will be given on friendly environment as a family. As we all know that most of the companies which are into services, included hospitality industry have long working hours and shifts. So if they do not get feasible working environment on the work place then they would not be able to work for long time in same company. Which results Turnover, not committed and less satisfied. Employees of that company always look for another opportunity and they will look for a change. At the end, it would be loss for the company. The top management have to look at the situation to resolve actual fault. In case of ignorance these companies would not service longer in the market.

\section{Findings and Conclusion}

This study come up with the new idea and exploring the sycophantic behaviour that how it positively affects to the organisational environment and also discussed reasons to grow more in the market. This paper basically explained answers of two questions which are mainly issue in today world and with the help of previous studies we giving the answer how employee use sycophantic behaviour to gain competitive advantage and various advantages like Promotion, Transformation, Decision making and also interfere in Recruitment and Selection process. This paper also discussed that how trust and communication is crucial in today competitive environment to compete in the market and also discussed the various advantages. As proper communication resulted, job satisfaction and Long term commitment, Increase productivity and efficiency which reduces turnover, absenteeism and increase the commitment of the employees. The study also concluded that sycophantic behaviour had positive impact on Promotion, Transformation, in decision making processes and making selections.

\section{Recommendations}

1) There are various other factors which also influence to sycophantic behaviour of employee and their impact can be seen on Organisation Environment. This will be considering in future research.

2) Only secondary data has been used in this study. So we will try to put more effort, and will do some primary studies soon.

\section{References}

1. Ekong CN, Essien EB (2012) The Economics of Gangsterism and Sycophancy in Nigerian Politics. Current Research Journal of Social Sciences 4: 277-284

2. Jhatial AA, Mangi RA, Ghumro IA (2004) Antecedents and consequences of employee turnover: Empirical evidence from Pakistan. British Journal of Management \& Economics 2

3. Ayodele O (1988) Objectivity, Sycophancy and the Media Reality in Nigeria Africa Media Review 3: 106-120.

4. Henry P (2009) The Sycophantic Culture. United States of America.

5. Obaze A, Fashanu F (2006) Mass communication law and ethics. Safinos Publishers, Ibadan.

6. Okunna S (2003) Ethics of mass communication. New Generation Ventures Ltd, Enugu.

7. Richie YG (2011) Politics of Sycophancy. Attribution Non-commercial.

8. Judge T, Bretz R (1994) Political influence behaviour and career success Journal of Management 20: 43-65.

9. Thacker R, Wayne S (1995) An examination of the relationship between upward influence tactics and assessments of promotability. Journal of Management 21: 739-756

10. Drane KJ (2006) What is the Relationship among Sycophantic Behavior Supervisor-subordinate Communication, Co-worker Relationships and Trust. Journal of Undergraduate Research, The Murray State University 2: 11-18

11. Umeogu B, Ojiakor I (2012) Sycophancy and Objective Journalism. Advances and applied sociology 2: 159-166. 
Citation: Chahal HS, Poonam B (2015) The Impact of Employee Sycophantic Behaviour on Organisation Environment: A Conceptual Study of Hospitality Sector in India. Arts Social Sci J 6: 117. doi:10.4172/2151-6200.1000117

Page 4 of 4

12. Mangi AR (2012) Human resource management practices in private sector organisations in pakistan: study of cultural influences. Global journal of management and business research 12 .

13. Krafft $P$, Engelbrecht AS, Theron CC (2004) The Influence of Transformational and Transactional Leadership on Dyadic Trust Relationships through Perceptions of Fairness. Journal of Industrial Psychology 30: 10-18

14. Cool J, Wall T (1980) New work Attitude Measures of Trust, Organisation Commitment and Personal Need Nonfulfillment. Journal of Occupational Psychology 53: 39-52 